\title{
SIMS (Imaging Secondary lon Mass Spectrometry) Analysis of a Cross-section Sample From Leonardo Da Vinci's Adoration of the Magi
}

Hua Tian ( $\sim$ hut3@psu.edu)

Pennsylvania State University University Park: The Pennsylvania State University - University Park Campus https://orcid.org/0000-0002-3598-0219

Maurizio Seracini

Editech Art \& Science

Katherine Schimmel

Independant Reseacher

Stephen J. Benkovic

Pennsylvania State University University Park: The Pennsylvania State University - University Park

Campus

Nicholas Winograd

Pennsylvania State University University Park: The Pennsylvania State University - University Park Campus

\section{Research article}

Keywords: C60 Time-of-Flight secondary ion mass spectrometry (ToF-SIMS), High-resolution mass spectrometry imaging (MSI), Leonardo da Vinci's Adoration of the Magi, Material characterization of paint film, Scanning electron microscopy with energy dispersive X-ray spectroscopy (SEM-EDX)

Posted Date: October 29th, 2020

DOl: https://doi.org/10.21203/rs.3.rs-97371/v1

License: (c) (1) This work is licensed under a Creative Commons Attribution 4.0 International License.

Read Full License 


\title{
SIMS (Imaging Secondary Ion Mass Spectrometry) Analysis of a Cross-Section Sample From Leonardo da Vinci's Adoration of the Magi
}

Hua Tian ${ }^{1}$, Maurizio Seracini ${ }^{2}$, Katherine Schimmel ${ }^{3}$, Stephen J. Benkovic ${ }^{1}$ and Nicholas Winograd ${ }^{1}$

1 The Department of Chemistry, Pennsylvania State University, US

2 Editech Art \& Science, Florence, Italy

3 Independent researcher, Florence, Italy and San Diego, CA.

\begin{abstract}
Paintings often consist of highly complex layered structures that contain a mixture of organic and inorganic materials at each layer depending upon the artist's technique. A comprehensive analysis of the chemical composition could provide critical information on the sequence of events that led to an artwork's current state. In this investigation, we have employed a novel imaging technique known as Secondary Ion Mass Spectrometry (SIMS) to chemically map the cross-section of a paint film sampled from Leonardo da Vinci's Adoration of the Magi at a submicron resolution using a $\mathrm{C}_{60}{ }^{+}$ion source. A wide range of materials were found to be spatially localized at the different layers such as: protein, carbon, silicates, fatty acids, salts and lead associated compounds. An interaction of chloride salts with the lead white was observed in the priming layer. The chloride salts disrupted most of the priming layer suggesting that a cleaning process took place that removed most of the priming layer before the monochrome brown repaints were added on top at a later time.
\end{abstract}

Keywords: $\mathrm{C}_{60}$ Time-of-Flight secondary ion mass spectrometry (ToF-SIMS), High-resolution mass spectrometry imaging (MSI), Leonardo da Vinci's Adoration of the Magi, Material characterization of paint film, Scanning electron microscopy with energy dispersive X-ray spectroscopy (SEM-EDX).

\section{Introduction}

In 1481, the canons regular of Saint Augustine commissioned Leonardo da Vinci to paint an altarpiece for the church of San Donato a Scopeto, located just outside the city walls of Florence. The subject of the painting was the Adoration of the Magi. Leonardo worked on the painting until early 1482 but left it unfinished when he went to Milan at the behest of Duke Ludovico Sforza. Having waited thirteen months for Leonardo's return, the monks commissioned another altarpiece of the Adoration to Filippino Lippi (1457-1504), who completed his work in 1496. 
Not much is known about what happened to Leonardo's Adoration from 1481 to 1621, when it was reported among the belongings of Don Antonio de Medici. And it is only in 1670 that the painting was brought to the Uffizi, as it is recorded in the register of the Medici wardrobe.

In 2001, the Uffizi Gallery commissioned Maurizio Seracini to conduct a diagnostic investigation on Leonardo's The Adoration of the Magi. The purpose of the investigation was to characterize the painting technique, the materials used in the execution of the work and its state of conservation in order to assess whether it was both necessary and appropriate for the painting to be restored. The scientific survey was sponsored by Dr. Loel Guinness, founder of the Kalpa Group, an independent organization that supports the work of individual scholars and professionals across a wide research spectrum. Initially, extensive research was conducted on the historical events that could have determined the painting's current state of conservation. Then, a two-phase scientific examination, consisting of multispectral diagnostic imaging, coupled with highly specific analytical diagnostics, followed.

During the first stage of the investigation, a comprehensive program of diagnostic imaging was carried out in which the images of the painting, taken at specific wavelengths, became the subject of both comparative and layered readings. This was achieved by superimposing the various images of the painting from the surface layer all the way down to the wooden support. The results of these readings, in addition to qualitatively characterizing the technical execution of the work and revealing an extraordinary drawing concealed underneath the monochrome painting, also helped identify the areas where samples were going to be taken so that their complex array of organic and inorganic compounds could be studied using highly specific chemical imaging techniques. These techniques included scanning electron microscopy with energy dispersive X-ray spectroscopy (SEM-EDX), which spatially localizes elemental ions with fine details of morphology, ${ }^{5-6}$ and secondary ion mass spectrometry (SIMS), which provides more specific molecular information about the chemical distribution of materials of the paint film.

SIMS has demonstrated an unprecedented resolution in visualizing the distribution of all the components ${ }^{7-10}$. With mass spectrometry, specific molecules can be characterized by directly determining their molecular mass and numerous compounds can be identified simultaneously in a single run. For these analyses, a paint sample is bombarded with a beam of energetic particles focused on a sub-micron spot. These incident particles cause desorption of ionized molecules from the top few molecular layers of the sample. The mass spectra of these desorbed molecules can then be quickly determined. Imaging is performed by scanning the beam across the sample and then acquiring spatially resolved mass spectra on the fly. A typical image consists of up to 100,000 individual mass spectra, each associated with a specific $\mathrm{x}$, y coordinate on the sample. Once this data set has been acquired, it is possible to extract the intensity of specific masses at each coordinate and to view separately a molecule-specific image of each chemical compound of interest.

For the studies presented here, a unique bombarding particle was chosen to be $\mathrm{C}_{60}{ }^{+}$(Buckminsterfullerene) accelerated to a kinetic energy of 40,000 eV. This projectile is preferable because it leaves a much smaller residue of chemical damage on the sample surface than many other atomic or molecular projectiles. The spatial resolution using this projectile is below 1 
micron, depending upon the field of view ${ }^{11-13}$. The resolving power of the mass spectrometer $\mathrm{m} / \Delta \mathrm{m}$ is 6000 over the entire mass range $(\mathrm{m} / \mathrm{z} 30-\mathrm{m} / \mathrm{z} 800)$. With this setup, an unprecedented chemical resolving power at a submicron resolution was achieved which allowed us to scrutinize the chemical composition and uncover new evidence relating to the specific events that occurred over the course of the painting's history.

Previously, SEM EDX analysis of cross-sections of paint samples of the Adoration of the Magi showed that the lead white priming layer (that was brushed over the underdrawing to protect it and keep it visible to the artist so that it could guide him during the painting's execution), was damaged in several areas by what appeared to be a cleaning solvent.

Here we describe how High-resolution SIMS imaging on a cross-section was instrumental in tracing the spatial distribution of the cleaning solvent and its interaction with the priming layer.

\section{Methodology and materials}

\section{Sample surface preparation}

A microsample was taken from Leonardo da Vinci's Adoration of the Magi for SIMS analysis. The sample numbered S16 was extracted from the horseman on the left side of the painting in the region that is composed of a dark brown brushstroke and that outlines the horseman's body. This sample was embedded in polyester resin and polished to expose a flat surface. The resulting cross-section revealed the different paint layers as follows: the ground, the priming, a dark layer, and finally, a layer of varnish on the top.

\section{SEM imaging}

Scanning Electron Microscopy-Energy Dispersive Spectroscopy (SEM-EDS) was employed to characterize the elemental composition of two areas of interest on the cross-section circled in Figure 1 (b). A $20 \mathrm{keV}$ electron beam was finely focused on the cross-section of the paint film to reveal the topography across the entire surface.

\section{SIMS imaging and data processing}

High resolution SIMS imaging was performed on the sample using a novel DC beam buncher-ToF SIMS instrument, J105 3D Chemical Imager. In order to reveal the details of the chemical composition of the different paint layers, regions of interest, AOI 1-4 were imaged at varying resolution as in Figure (b). A larger area of $300 \times 150 \mu \mathrm{m}^{2}$ located in the middle of the section AOI1, was imaged at a spatial resolution of $0.6 \mu \mathrm{m}$. While a higher spatial resolution of $0.3 \mu \mathrm{m}$ was adopted to scan a smaller area of $80 \times 80 \mu \mathrm{m}^{2} \mathrm{AOI} 2$, on the left and for more detail as in Figure b. For the comprehensive profiling, both positive and negative ions were acquired. AOI3, comprised of $200 \times 100 \mu \mathrm{m}^{2}$ was imaged in positive mode, while AO14 with the same area was imaged in negative mode. The spatial resolution for AOI3-4 was $0.4 \mu \mathrm{m}$.

The image data was analyzed using an Ionoptika Image Analyzer (2.0.2.11). The peak center and isotope pattern were then used to assign the ions of interest and to determine which localizations are generated as ion maps with a thermal scale. To avoid interference, only a 0.05 mass window of the ion center was selected for the ion maps. Additionally, the SEM image was employed in order to superimpose it onto specific ion maps so that it may then be correlated with a specific layer. Color overlay maps were also generated in order to elucidate the spatial correlation of the different ions. 


\section{Results and discussion}

Contour of the paint sample

Several compounds, along with their distribution, were used for assessment, to eliminate the chemical diffusion and mass interference of the polyester resin around the cross-section. In Figure 2 (1), Potassium ion $\mathrm{K}^{+}$at $\mathrm{m} / \mathrm{z} 38.97$ reveals the clear outline of the paint sample above the ground layer. Moreover, the area of resin can be localized by carbon cluster and carbon hydrates, $C_{n}(n=4-15)$ and $\mathrm{C}_{n} \mathrm{H}^{+}(n=4-15)$ respectively. The representative image is shown in Figure 2 (e) with $\mathrm{C}_{10}{ }^{+}$at $\mathrm{m} / \mathrm{z}$ 120.00. Interestingly, according to the superimposed SEM image, $\mathrm{C}_{10}{ }^{+}$is also localized in a brownish layer which lies under a radiopaque layer. This dark brown layer contains carbon black and other organic material rather than being an indication of any contamination arising from the resin. It is clear that each layer on the cross-section contains distinct chemical markers that are either inorganic or organic; this is revealed by the color overlay of SIMS images in positive and negative mode in Figure 2 (a) and Figure 3 (a). Furthermore, these images have validated our method of sample preparation since there has been no chemical delocalization or diffusion of the embedding resin.

\section{Varnish layer}

The varnish layer of S16 may be identified as the thicker layer that lies just above the thin opaque layer in the SEM image. It should be noted that various organic and inorganic materials were found in this layer. This includes the aluminosilicates seen in Figure 2 (b and c) and Figure 3 (d) in both positive and negative images. We note, however, the major component is a protein-like organic material that is clearly identified by a unique protein fragment: $\mathrm{C}_{3} \mathrm{~N}^{-}$at $\mathrm{m} / \mathrm{z} 50.00^{14}$ as seen in Figure 3 (b). The phosphates $\mathrm{PO}_{2}{ }^{-}, \mathrm{PO}_{3}{ }^{-}$at $\mathrm{m} / \mathrm{z} 62.97$ and 78.96 are also scattered in the varnish layer as in Figure 3 (e).

\section{Radiopaque layer}

The radiopaque layer that is present underneath the varnish layer is demarcated by a thin white line in SEM image: Figure 1 (b). For the most part, this layer is composed of the same components as the ground layer, $\mathrm{Ca}, \mathrm{CaO}, \mathrm{CaOH}^{+}$and $(\mathrm{CaO})_{2} \mathrm{H}^{+}$ as in Figure $2(\mathrm{~d}$ and $\mathrm{m}$ ) and aluminosilicates as in Figure 2 ( $\mathrm{b}$ and c). As previously described in the section on the ground layer, the migration of calcium from the ground layer to the top layer is the result of a continuous aging process. Other components of interest in this layer are lead carbonate $\mathrm{PbC}_{2} \mathrm{O}_{2}{ }^{+}$at $\mathrm{m} / \mathrm{z} 263.96$ (Figure $2 \mathrm{f}$ ) and lead oxide $\mathrm{Pb}_{2} \mathrm{O}^{+}$at $\mathrm{m} / \mathrm{z} 430.0$ (Figure $2 \mathrm{k}$ ). These are both due to the interaction of lead with a binding material.

\section{Lead white layer}

SEM-EDS revealed a widespread disrupted priming layer that contains granules of lead white that have detached from the priming and then scattered and mixed with the upper layers. The elemental analysis of this layer pointed to the presence of chlorine, which is mainly associated with the lead in the lead white of the priming as seen in Figure 1 (c and d).

Our study also indicates that chlorine was not identified within the largest clusters of the lead white. This suggested a possible secondary reaction occurred between the chlorine and the lead of the priming, which would effectively rule out the hypothesis that chlorine was originally an impurity of lead, but rather that chlorine salts came into contact with lead and then collected around it, as other analyses were able to demonstrate. We were able to further validate this phenomenon by high resolution SIMS imaging. 
In order to correlate the signature ions within the different polarities in the lead white layer, the SIMS images were performed in exactly the same region, AOI1 (Figure 1, b) in both positive and negative mode. The distribution of a few key inorganic compounds is summarized in the color overlay image shown in Figure 4 (a). The major mass spectral peaks for the ground layer, shown in green, arise from $\mathrm{Ca}^{+}$and $\mathrm{CaOH}^{+}$. Of special interest here is the lead white layer shown in light blue and represented by the $\mathrm{Pb}$ mass spectral signal. In the overlay representation, the $\mathrm{Pb}$ signal is seen distributed throughout this layer. We also take note of several "hot spots" associated with $\mathrm{NaCl}$ and $\mathrm{KCl}$ as designated by the mass spectral cluster ion $\mathrm{NaKCl}^{+}$, shown in red.

The $\mathrm{Pb}$ white layer exhibited a complex chemistry as indicated by the careful examining of the mass spectra within this region. The principle ions for this region are shown in Figure 4 (b-e) and comprise $\mathrm{Pb}$-oxides, salt complexes of $\mathrm{Pb}, \mathrm{KCl}$ and $\mathrm{NaCl}$, as well as $\mathrm{PbCl}_{2}$. Note that these distributions are quite distinct and can clearly be seen in the color overlay images shown in Figure 4 (f, g). The images also show that the $\mathrm{Pb}$ particles are surrounded by $\mathrm{PbCl}_{2}$ and have salts distributed throughout the layer. Interestingly, the potassium chloride and lead chloride are more intense at the bottom rather than the upper portion of the lead white layer. Furthermore, chloride salt deposition confirms that the priming layer, which forms the bottom white lead layer, has been disrupted with a strong chloride solvent. Over the thin brown layer of glue, placed between the priming layer and the ground Fig 1 (a), there is a specific ion represented by lead oxide $\mathrm{Pb}_{2} \mathrm{O}^{+}$at $\mathrm{m} / \mathrm{z} 430.00$, as seen in Figure $2(\mathrm{k})$. This thin layer can be identified as the leftover of the priming material that remained undamaged after the cleaning procedure.

The chemistry of the different morphologies associated with the lead-white layer is revealed in the SEM images. As shown in Figure 5 (a), there are regions where granules of just a few microns in diameter can clearly be seen and are highlighted by the circle. A high-resolution SIMS image was generated from an $80 x 80 \mu \mathrm{m}^{2}$ area within the green rectangle as shown in Figure 5 (b). From selected ion images, the SIMS experiments clearly show that these granules consist of lead chloride and are of a different chemistry than of other regions located on the lead white layer.

Finally, in regions AOI 1-4, organic components such as fatty acids are detected at low intensities but without specific localization. Considering that the section surface has been exposed to the air for 15 years before SIMS measurement, it is likely that the organic binding media have degraded even further. In order to compensate for this and to investigate more pristine organic components, the section's surface was trimmed down by $100 \mathrm{~nm}$ to expose a new subsurface for the SIMS measurement (Figure 6, a). As expected, the fatty acids with a higher signal level were localized within a lead white layer in the region of AOI5 $\sim 520 \times 130 \mu \mathrm{m}^{2}$, including: palmitoleic acid at $\mathrm{m} / \mathrm{z} 253.22$, palmitic acid at $\mathrm{m} / \mathrm{z} 255.23$, linoleic acid at $\mathrm{m} / \mathrm{z} 279.23$, oleic acid at $\mathrm{m} / \mathrm{z} 281.24$ and stearic acid at $\mathrm{m} / \mathrm{z} 283.26$ (Figure 6, b). The ratio of the ion intensities palmitoleic : palmitic : linoleic : oleic : stearic $=0.29: 1: 0.13: 0.24: 0.65$, indicating that the most abundant fatty acids are palmitic and stearic acid. Their localization (Figure 6,b) is within the lead white layer and contains several hot spots. Due to the process of aging and degradation, it is difficult to determine the type of binding oil used. However the chemical composition of fatty acids suggests that the binding media used are associated with linseed oil, and that the ratio variation of detectable fatty acids is likely linked to the aging of the paint films ${ }^{15-16}$. 


\section{The origin of chloride in the lead white layer}

Chlorine, which is mainly associated with the lead white of the priming, was found in previously examined samples with a wider distribution occurring in the lower part of the painting. We note that the presence of chlorine in paint layers is not in itself unusual and is well documented in the literature. However, it generally refers to small quantities of chlorine which can be assumed to be atmospheric (for instance, in certain particular areas near the sea) or linked to the manufacturing processes of the lead white itself (i.e., horse urine) ${ }^{17}$. In other instances, strong cleanings done in the past have been associated with the use of chlorine.

We can rule out that the chlorine present in the Adoration was due to the way in which the lead white of the priming was manufactured, because chlorine is more concentrated around large clusters of lead white and is less present (or is indeed totally absent) within them. Additionally, the lead white layer is discontinuous and disrupted as revealed by the SEM-EDS and SIMS analyses. Atmospheric origin can also be ruled out, given that the elevated amount of chlorine detected in the painting is concentrated more in the inner than the outer layers. Therefore, it can be concluded that a chlorine-based solvent was used on the priming layer during a cleaning.

In the priming layer and in the region of the sky (which represents the earliest stage of execution of the painting and should be considered the work of Leonardo), a high concentration of chlorine associated with lead white was identified (in other samples previously examined with SEM), with the formation of lead chlorides, together with minor amounts of other chlorides (mainly potassium and sodium), as mentioned earlier. The presence of small amounts of chlorine in the upper layers could be related to the migration of ions through the various layers.

Finally, we conclude that the most plausible hypothesis is that at some time, after Leonardo left the work unfinished at the priming and sky layers, the painting was cleaned using chlorine-based solvents. Furthermore, the careful study of crosssections confirmed that the type of disruption suffered by the priming was not identified in any of the overlying painting layers. Thus, it is clear that such an intervention occurred prior to the execution of paint layers that were placed over the priming and the sky.

\section{The light brown layer between the lead white layer and the ground layer}

A thin layer composed of a brown color can clearly be observed between the lead white layer and the ground layer as seen in microscopy Figure 1 (a) image. It also appears that lead oxide $\left(\mathrm{Pb}_{2} \mathrm{O}^{+}\right.$at $\left.\mathrm{m} / \mathrm{z} 430.00\right)$, which sits over the brown layer, is localized in this layer (Figure 2k). As already mentioned, previous analysis with micro-FTIR and a staining test done with a Ponceau S (Acid Red 112), a colorant for proteins, confirmed that this layer is comprised of animal glue. However, SIMS imaging did not detect any organic layers in this region, as shown in Figure 2 (a) most likely due to the subsequent mixing and breaking down of organic materials during the cleaning process using a chloride solvent.

\section{The ground layer}


The light beige layer of the Ground, which constitutes the largest uniform region in the entire cross-section, is comprised of various metal ions along with their associated oxides, hydroxide and salt adduct. Calcium ions $\left(\mathrm{Ca}^{+}, \mathrm{m} / \mathrm{z} 39.96 ; \mathrm{CaOH}^{+} \mathrm{m} / \mathrm{z}\right.$ 56.96 (Figure $2 \mathrm{~d}$ ); $(\mathrm{CaO})_{2} \mathrm{H}^{+}, \mathrm{m} / \mathrm{z} 112.92$ (Figure $2 \mathrm{~m}$ ) are mainly localized in the ground layer. Sulfates $\left(\mathrm{SO}_{3}{ }^{-} \mathrm{m} / \mathrm{z}^{-} 79.95\right.$ and $\mathrm{SO}_{4}^{-} \mathrm{m} / \mathrm{z}$ 95.95) in Figure 3 (i), are exclusively localized in the ground layer. Silicates and aluminates $\left(\mathrm{SiO}_{2} \mathrm{Al}_{2} \mathrm{OH}^{+} \mathrm{m} / \mathrm{z}\right.$ 130.90; $\mathrm{SiO}_{2} \mathrm{Al}_{2}(\mathrm{OH})_{2} \mathrm{H}^{+}, \mathrm{m} / \mathrm{z} 148.90$ (Figure $\mathrm{c}$ and e) may also be found in the ground layer and suggests that these ions can be attributed to aluminosilicates which are most likely indicative of clay-based earth pigments.

\section{Conclusion and outlook}

High resolution SIMS imaging has been employed to reveal the complex chemistry on a cross-section of a paint sample taken from Leonardo da Vinci's Adoration of The Magi. Here, distinct chemical signatures were associated with different painting layers benefiting from the $1 \mu \mathrm{m}$ spatial resolution and chemical sensitivity of the $\mathrm{C}_{60}$ source. With a special focus on the priming layer, it became possible to scrutinize the spatial correlation of lead, lead oxide, organic lead and chloride in the cross-section, suggesting that a possible secondary reaction phenomena occurred between the chlorine and the lead of the priming, rather than the chlorine being an impurity of the lead.

In addition, Chloride and its salt adducts (e.g., potassium chloride and lead chloride) were found to be concentrated at the bottom of the priming, strongly indicating that the cause of such an unusual decay of the priming layer was due to a prior cleaning that was done with a chlorine-based solvent which removed and disrupted most of the priming layer before the monochrome layers were added at different times. Moreover, additional SEM-EDX studies on other cross-sections confirmed that the type of damage suffered by the priming was not identified in any of the overlying painting layers.

These findings are significant as they prove that the monochrome painting seen for centuries, is not contemporary to the priming layer or to the execution of the sky but rather, was the result of one or more later repaints which cannot be attributed to Leonardo.

Finally, this study has shown that SIMS imaging is a powerful diagnostic tool to identify and spatially localize the multiple components found in the complex structure of paint films at a submicron resolution. Here, as we've shown, SIMS imaging can be valuable in uncovering the sequence of events relating to the history and aging process of art works.

\section{List of abbreviations}

SEM-EDS: Scanning Electron Microscopy/ Energy Dispersive X-ray Analysis

SIMS: Secondary Ion Mass Spectrometry

FTIR: Fourier transform infrared spectroscopy

XRF: X-ray fluorescence

\section{Acknowledgements}


We are very grateful for the unique opportunity to work on a sample from a painting by Leonardo da Vinci. This project represents an interdisciplinary collaboration that started some years ago and that has brought together participants from around the world both in academia and the private sector. Our effort was driven by the singular focus of gaining new insights into one of the world's greatest masterpieces. We also feel that our approach is very much in the spirit of the artist.

We are deeply indebted to Professors Stephen Benkovic and Nicholas Winograd for their unwavering enthusiasm, patience and encouragement throughout the entire project. To the former, we owe the additional thanks of providing us with the valuable connection to Professor Winograd. And to latter, we owe our deep gratitude for providing the lab facilities along with the personnel for the SIMS high resolution imaging equipment.

The scientific study on Leonardo's Adoration of the Magi originally began in 2001. The project was made possible through sponsorship provided by Dr. Loel Guiness and his Kalpa Group. We express our sincerest gratitude for his vision and generosity. The book, which will summarize the complete results of the scientific investigation of the painting is expected to be published by the end of 2020 .

\section{Authors' contributions}

MS and KS conceived the project. HT designed and performed the SIMS and SEM analysis, contextualized the data, and prepared the manuscript. MS provided the embedded cross-sample, interpreted and contextualized the data, and prepared the manuscript. KS contextualized the data and prepared the manuscript. SB oversaw the project. NW provided the instrumentation and funding for the SIMS measurement. All authors participated in the editing and reviewing of the paper.

\section{Funding}

Not applicable to current study. However, funding for prior study has been acknowledged previously.

\section{Availability of data and materials}

The datasets generated and/or analyzed during the current study are not publicly available due to the sensitive nature of the study but are available from the corresponding author upon reasonable request.

\section{Competing interests}

The authors report no conflict of interest with respect to current project but note that MS was commissioned by the Uffizi in 2001 to conduct a diagnostic investigation on The Adoration of the Magi.

\section{Author details}

Hua Tian, Associated Research Professor at Pennsylvania State University. Her research focus is on the high-resolution imaging of organic and inorganic surfaces and bulk using ToF-SIMS. She has also been involved in the development of a novel desorption source for high chemical sensitivity and submicron spatial resolution. 
Stephen James Benkovic, Evan Pugh Professor and Eberly Chair in Chemistry at Pennsylvania State University. His research has focused on mechanistic enzymology and the discovery of enzyme inhibitors. He was elected to the United States National Academy of Sciences in 1985.

Nicholas Winograd, Evan Pugh University Professor at Pennsylvania State University and an Elected Fellow of the American Association for the Advancement of Science. Professor Winograd has pioneered the cluster-SIMS for molecular imaging of organic material.

Maurizio Seracini, a pioneer in the use of multispectral imaging applied to works of art, in 1977 founded Editech, the first Diagnostic Center for Cultural Heritage in Italy. From 2007- 2012 he was the founder and director of CISA3 (Center of Interdisciplinary Science for Art, Architecture and Archaeology), at UCSD. Since 2015, he has been the Director of Art, Antiquity and Cultural Heritage Crime and Forensic Projects in the Graduate program in Homeland Security at San Diego State University.

Katherine Schimmel is an independent researcher and writer whose projects in the visual arts have focused on specific aspects relating to the material analysis and study of renaissance paintings.

\section{References}

1. Joseph, E.; Prati, S.; Sciutto, G.; Ioele, M.; Santopadre, P.; Mazzeo, R., Performance evaluation of mapping and linear imaging FTIR microspectroscopy for the characterisation of paint cross sections. Anal. Bioanal. Chem. 2010, 396 (2), 899-910.

2. Watts, K. E.; Lagalante, A. F., Method development for binding media analysis in painting cross-sections by desorption electrospray ionization mass spectrometry. Rapid Commun. Mass Spectrom. 2018, 32 (16), 1324-1330.

3. Adriaens, A.; Dowsett, M. G., Chapter 3 Electron microscopy and its role in cultural heritage studies. In Comprehensive Analytical Chemistry, Elsevier: 2004; Vol. 42, pp 73-128.

4. Lau, D.; Villis, C.; Furman, S.; Livett, M., Multispectral and hyperspectral image analysis of elemental and microRaman maps of cross-sections from a 16th century painting. Anal. Chim. Acta 2008, 610 (1), 15-24.

5. Malek, M. A.; Nakazawa, T.; Kang, H.-W.; Tsuji, K.; Ro, C.-U., Multi-Modal Compositional Analysis of Layered Paint Chips of Automobiles by the Combined Application of ATR-FTIR Imaging, Raman Microspectrometry, and SEM/EDX. Molecules (Basel, Switzerland) 2019, 24 (7), 1381.

6. Zadora, G.; Brożek-Mucha, Z., SEM-EDX—a useful tool for forensic examinations. Mater. Chem. Phys. 2003, 81 (2), 345-348.

7. Sanyova, J.; Cersoy, S.; Richardin, P.; Laprévote, O.; Walter, P.; Brunelle, A., Unexpected Materials in a Rembrandt Painting Characterized by High Spatial Resolution Cluster-TOF-SIMS Imaging. Anal. Chem. 2011, 83 (3), 753-760.

8. Richardin, P.; Mazel, V.; Walter, P.; Laprévote, O.; Brunelle, A., Identification of Different Copper Green Pigments in Renaissance Paintings by Cluster-TOF-SIMS Imaging Analysis. J. Am. Soc. Mass. Spectrom. 2011, 22 (10), 1729-1736. 
9. Mazel, V.; Richardin, P.; Touboul, D.; Brunelle, A.; Walter, P.; Laprévote, O., Chemical imaging techniques for the analysis of complex mixtures: New application to the characterization of ritual matters on African wooden statuettes. Anal. Chim. Acta 2006, 570 (1), 34-40.

10. Keune, K.; Hoogland, F.; Boon, J. J.; Peggie, D.; Higgitt, C., Evaluation of the "added value" of SIMS: A mass spectrometric and spectroscopic study of an unusual Naples yellow oil paint reconstruction. Int. J. Mass spectrom. 2009, $284(1), 22-34$.

11. Wucher, A.; Cheng, J.; Winograd, N., Molecular depth profiling of trehalose using a C60 cluster ion beam. Appl. Surf. Sci. 2008, 255 (4), 959-961.

12. Cheng, J.; Kozole, J.; Hengstebeck, R.; Winograd, N., Direct comparison of Au3+ and C60+ cluster projectiles in SIMS molecular depth profiling. J. Am. Soc. Mass. Spectrom. 2007, 18 (3), 406-412.

13. Tian, H.; Six, D. A.; Krucker, T.; Leeds, J. A.; Winograd, N., Subcellular Chemical Imaging of Antibiotics in Single Bacteria Using C60-Secondary Ion Mass Spectrometry. Anal. Chem. 2017, 89 (9), 5050-5057.

14. Benetti, F.; Perra, G.; Damiani, D.; Atrei, A.; Marchettini, N., ToF-SIMS characterization of proteinaceous binders in the wall painting "Madonna and Child enthroned with Saints" by Ambrogio Lorenzetti in the St. Augustine Church (Siena, Italy). Int. J. Mass spectrom. 2015, 392, 111-117.

15. Colombini, M. P.; Andreotti, A.; Bonaduce, I.; Modugno, F.; Ribechini, E., Analytical Strategies for Characterizing Organic Paint Media Using Gas Chromatography/Mass Spectrometry. Acc. Chem. Res. 2010, 43 (6), 715-727.

16. Bonaduce, I.; Carlyle, L.; Colombini, M. P.; Duce, C.; Ferrari, C.; Ribechini, E.; Selleri, P.; Tine, M. R., New Insights into the Ageing of Linseed Oil Paint Binder: A Qualitative and Quantitative Analytical Study. PLoS One 2012, 7 (11).

17. van Loon, A.; Amsterdam, U. v.; MOLART, Color Change and Chemical Reactivity in Seventeenth-century Oil Paintings. Loon: 2008.

\section{Graphic abstract}

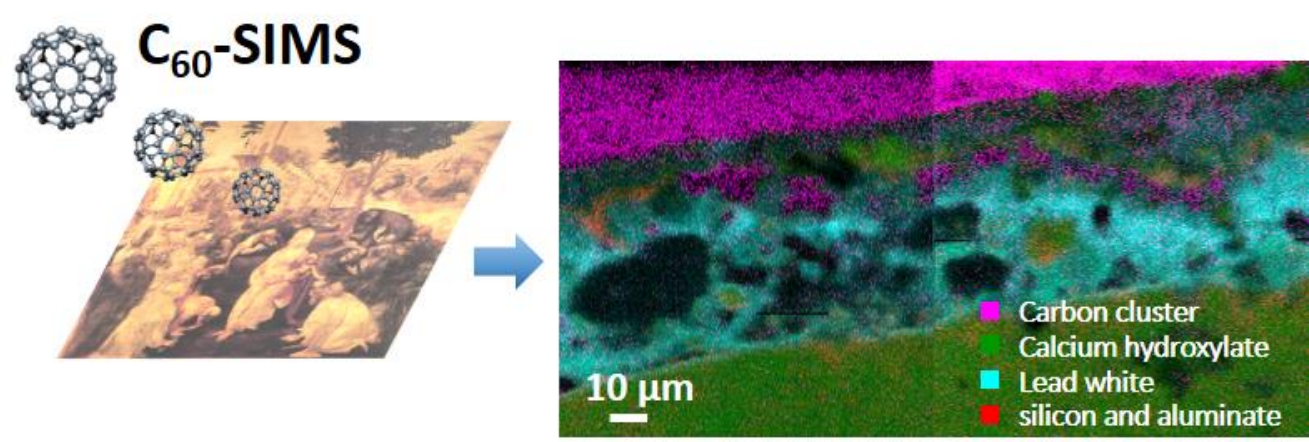



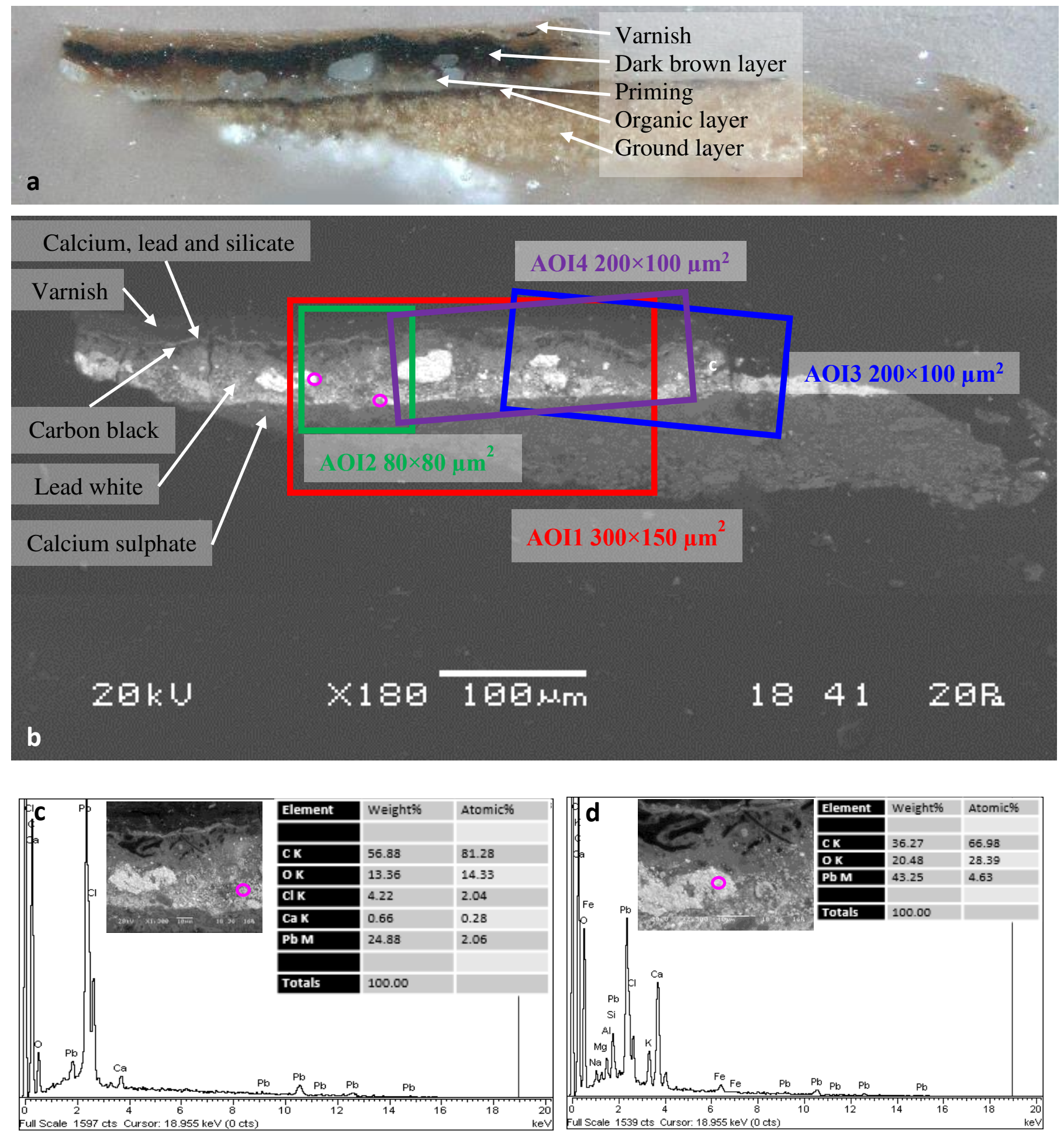

Figure 1. Optical (a) and SEM (b) images of the paint cross-section from the Adoration of the Magi. The three layers of interest are labeled in (a) and (b). The SIMS images were taken from the 4 areas of interest (AOI) shown in (b). Both negative and positive images were acquired in the areas in AOI 1-2, while only positive in the area in AOI3, negative in the area in AOI4. The areas within Magenta circles were subjected to SEM-EDS elemental analysis with result shown in (c) and (d). 


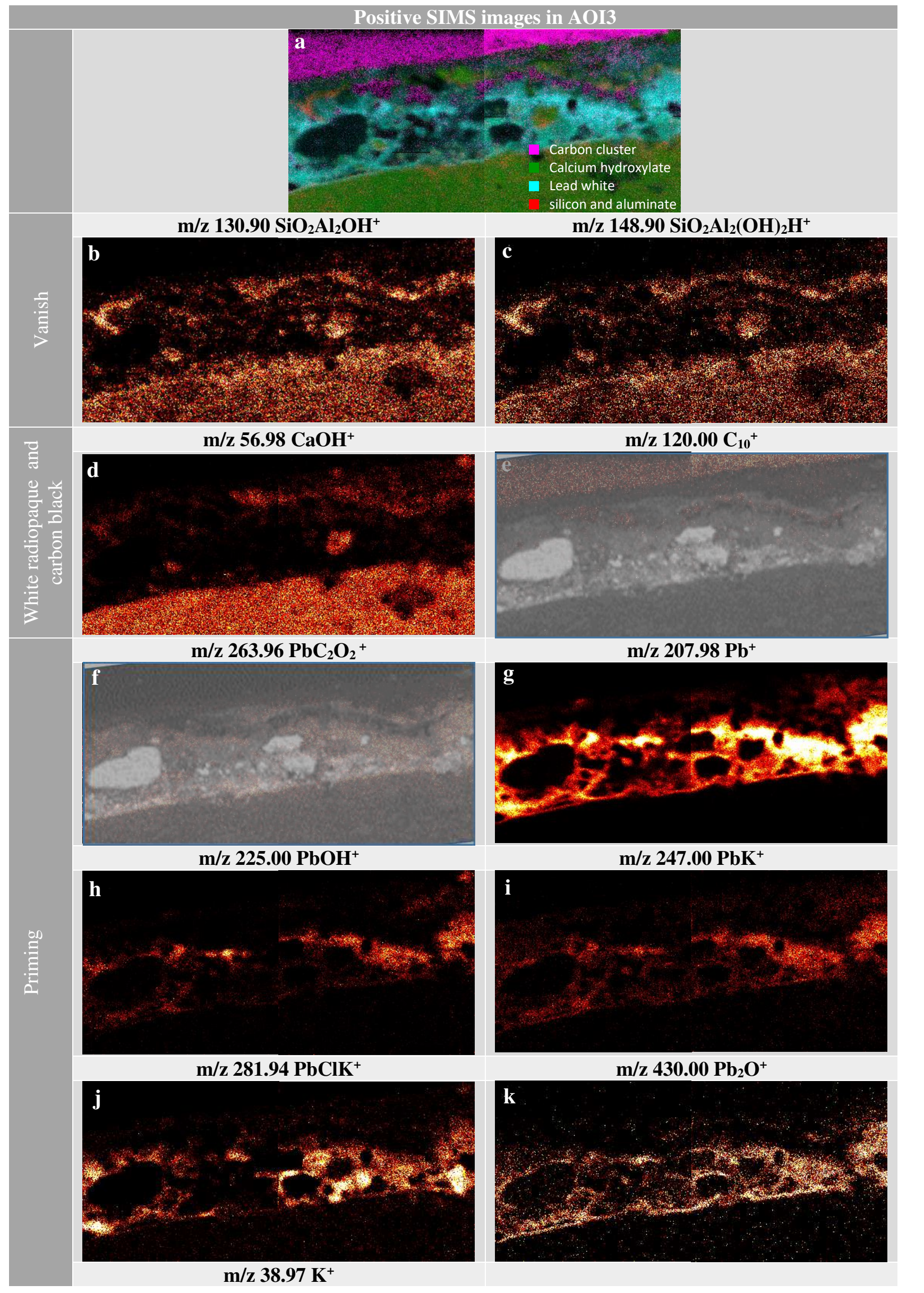




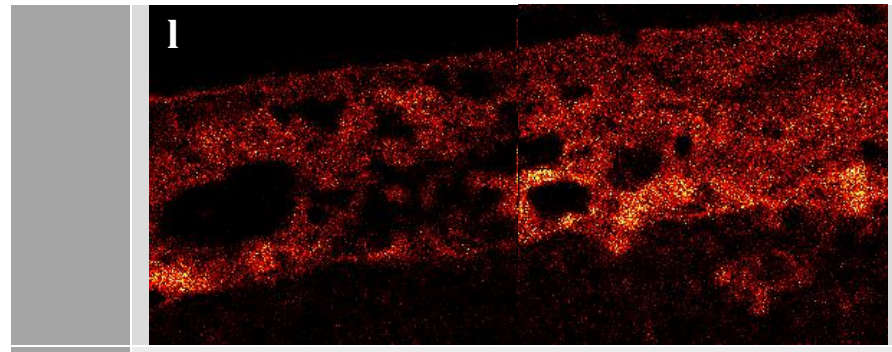

$\mathrm{m} / \mathrm{z} 112.95(\mathrm{CaO})_{2} \mathrm{H}^{+}$

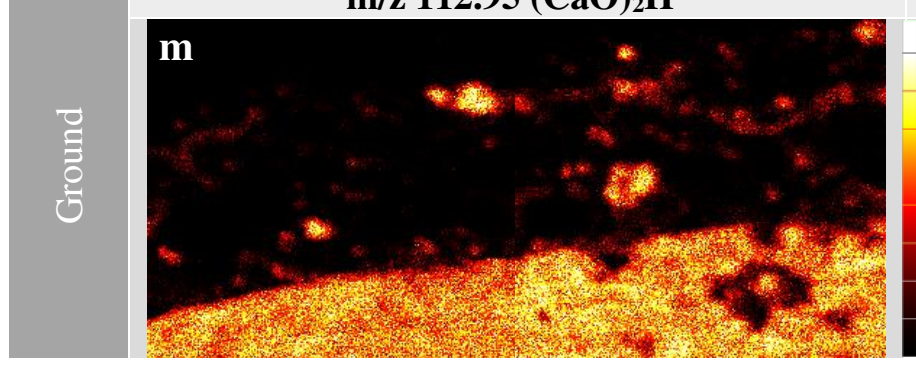

Figure 2 Positive images of paint film in areas of AOI 3 to reveal the chemical composition of each layers identified in SEM image. 


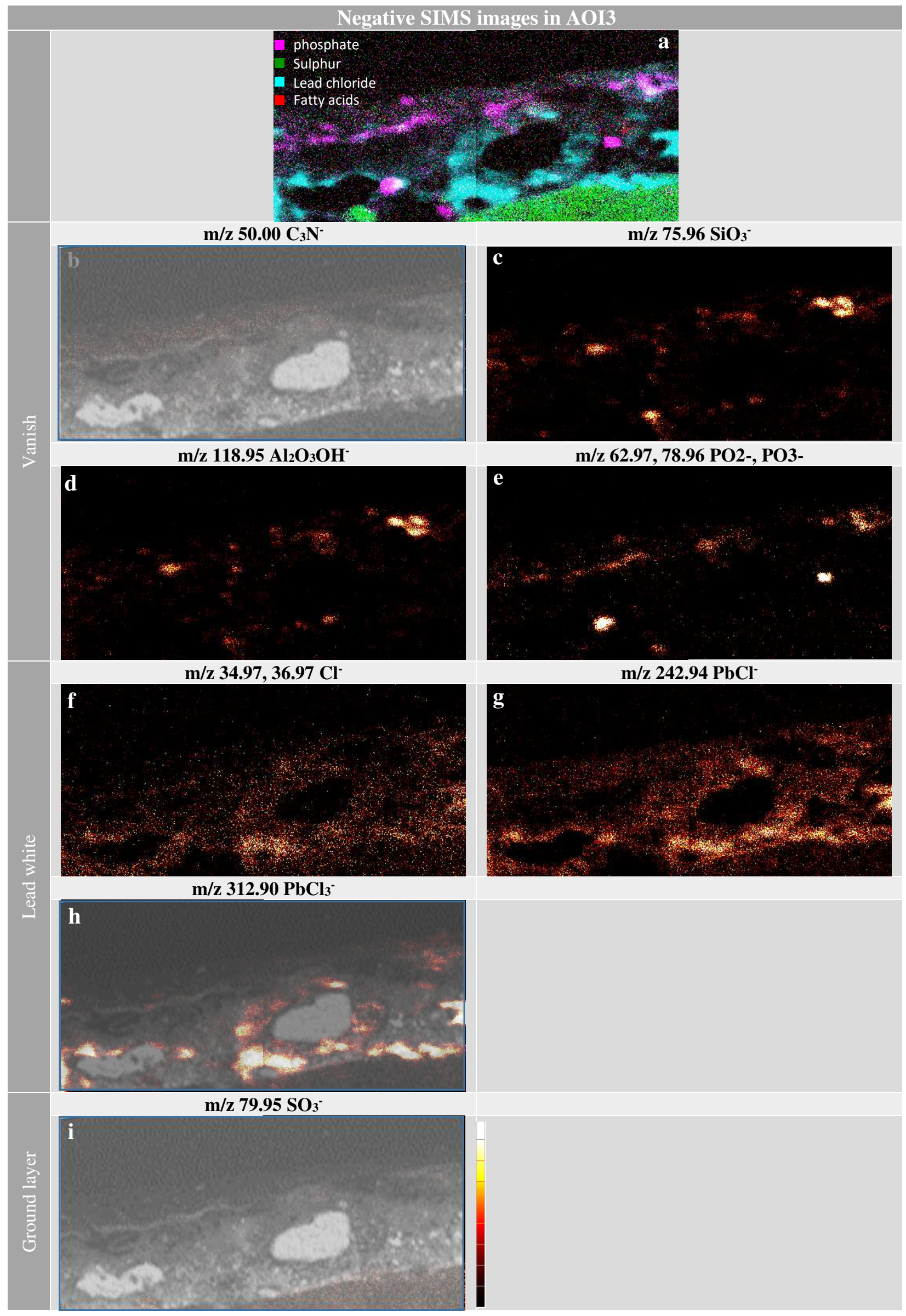

Figure 3 negative images of paint film in areas of AOI 4 to reveal the chemical composition of each layers identified in SEM image. 

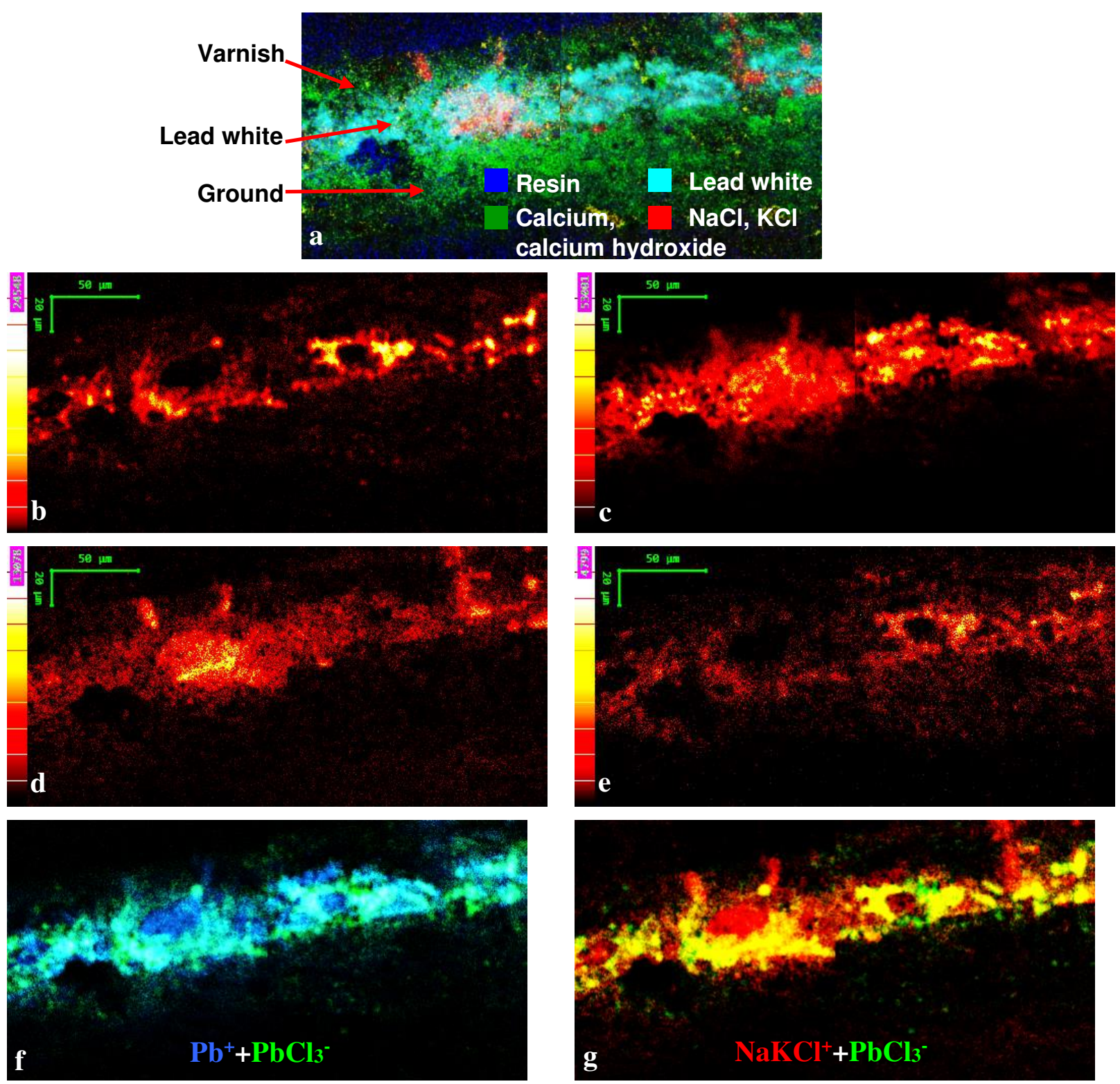

Figure 4 SIMS images from the lead white layer of the paint chip section. The color overlay image shown in (a) reveals the major inorganic components of the different layers, showing the embedding resin $(m / z, 85.01)$ in blue; calcium $\left(\mathrm{Ca}^{+}, m / z, 39.96\right)$ and calcium hydroxide $\left(\mathrm{CaOH}^{+}, m / z\right.$ 56.97) in green; lead ion $\left(\mathrm{Pb}^{+}\right.$, sum of $m / z$ 207.98, 206.98, 205.97, 203.97) in light blue; sodium potassium chloride $\left(\mathrm{NaKCl}^{+}, \mathrm{sum} \mathrm{of}\right.$ $m / z$ 96.92,98.92) in red, which is co-localized with lead ions; copper $\left(\mathrm{Cu}^{+}, \mathrm{m} / \mathrm{z}\right.$ 62.93) in yellow. Individual components are shown in b-e as follows: (b), $\mathrm{Pb}^{+}$, sum of $m / z$ 207.98, 206.98, 205.97, 203.97. Other positive ions such as $\mathrm{Pb}_{n}^{+}(\mathrm{n}=1-2), \mathrm{Pb}_{n} \mathrm{O}_{n}^{+}(\mathrm{n}=1-3), \mathrm{Pb}_{n} \mathrm{On}_{-1} \mathrm{OH}^{+}(\mathrm{n}=1-3)$ have the same distribution. $(\mathrm{c}), \mathrm{NaKCl}^{+}$, sum of $m / z$ 96.92, 98.92. Lead salt adducts $\mathrm{PbNaH}_{2}{ }^{+}, \mathrm{PbK}^{+}, \mathrm{PbO}_{2} \mathrm{Na}^{+}, \mathrm{PbClK}^{+}$show a similar distribution. (d), $\mathrm{PbCl}_{3}^{-}$, sum of $m / z$ 310.90, 311.90, 312.88, 313.89, 314.87, 315.89, 316.89. The $\mathrm{PbCl}^{-}$, $\mathrm{PbCl}_{2}^{-}$show the same distribution. (e) $\mathrm{HKCl}_{3}^{-}$, sum of $\mathrm{m} / \mathrm{z}$ 144.88, 146.88 and 148.87. The other chloride cluster ions with the same distribution are $\mathrm{NaCl}_{2}{ }^{-}, \mathrm{KCl}_{2}, \mathrm{H}_{2} \mathrm{O} \cdot \mathrm{KCl}_{2}^{-}$and $\mathrm{K}_{3} \mathrm{Cl}_{4}$. The relative intensity of these ions can be discerned from the scale bar on the left side of the image. The images in (f) and (g) show color overlays with $\mathrm{Pb}^{+}$in blue and $\mathrm{PbCl}_{3}^{-}$in green. (g) Color overlay image of $\mathrm{NaKCl}^{+}$in red and $\mathrm{PbCl}_{3}^{-}$in green. When the two ions are co-localized the color shows as yellow. 

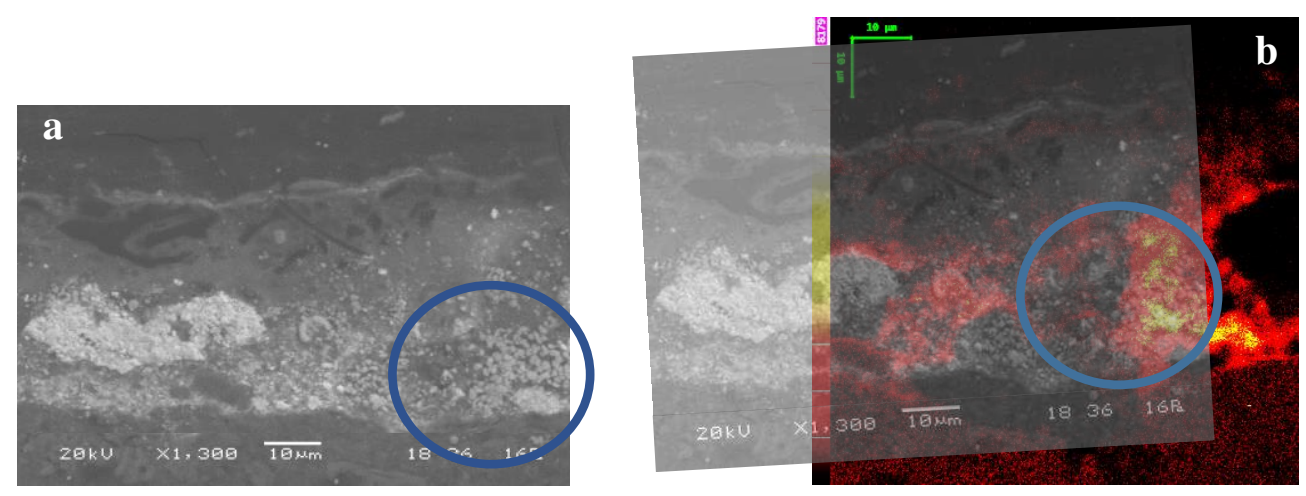

Figure 5 Small granules of micron dimension are revealed by the SEM image as designated by the blue circle in (a). The SIMS image (b) from this area shows that these granules consist of lead chloride (sum of $m / z 242.96,240.94$, 241.97, 243.94, 244.94). A semi-transparent version of the SEM image is superimposed upon the SIMS image to act as a guide to the eye. Related clusters, $\mathrm{PbClK}^{+}, \mathrm{Pb}_{2} \mathrm{Cl}^{+}, \mathrm{Pb}_{2} \mathrm{Cl}_{2}{ }^{+}$, exhibit the same distribution. 

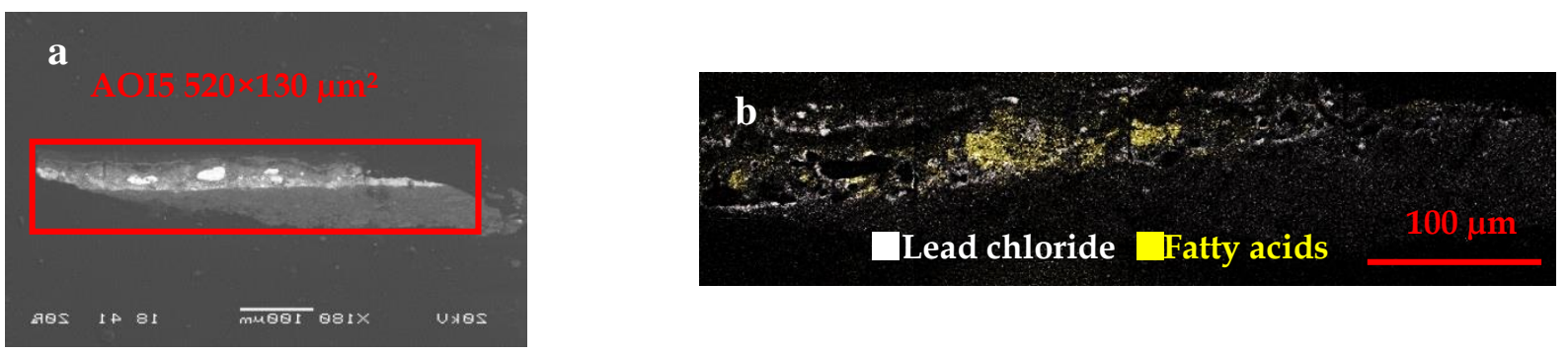

Figure 6 SIMS imaging of subsurface of paint sample to reveal the oil binding media in the lead white layer. (a) HR SIMS imaging was performance in the area of $520 \times 130 \mu^{2}$ with $2048 \times 512$ pixels as highlighted in SEM image of whole surface area. (b) Color overlay SIMS image of the fatty acids and lead chloride. Fatty acids at $\mathbf{m} / \mathbf{z} 255.26$ and 283.25 in yellow are localized within lead white layer characterized by $\mathrm{PbCl}+$ at $\mathrm{m} / \mathrm{z} 242.94$ in white. The composition of fatty acids suggests that the binding media is linseed oil. 


\section{Figures}
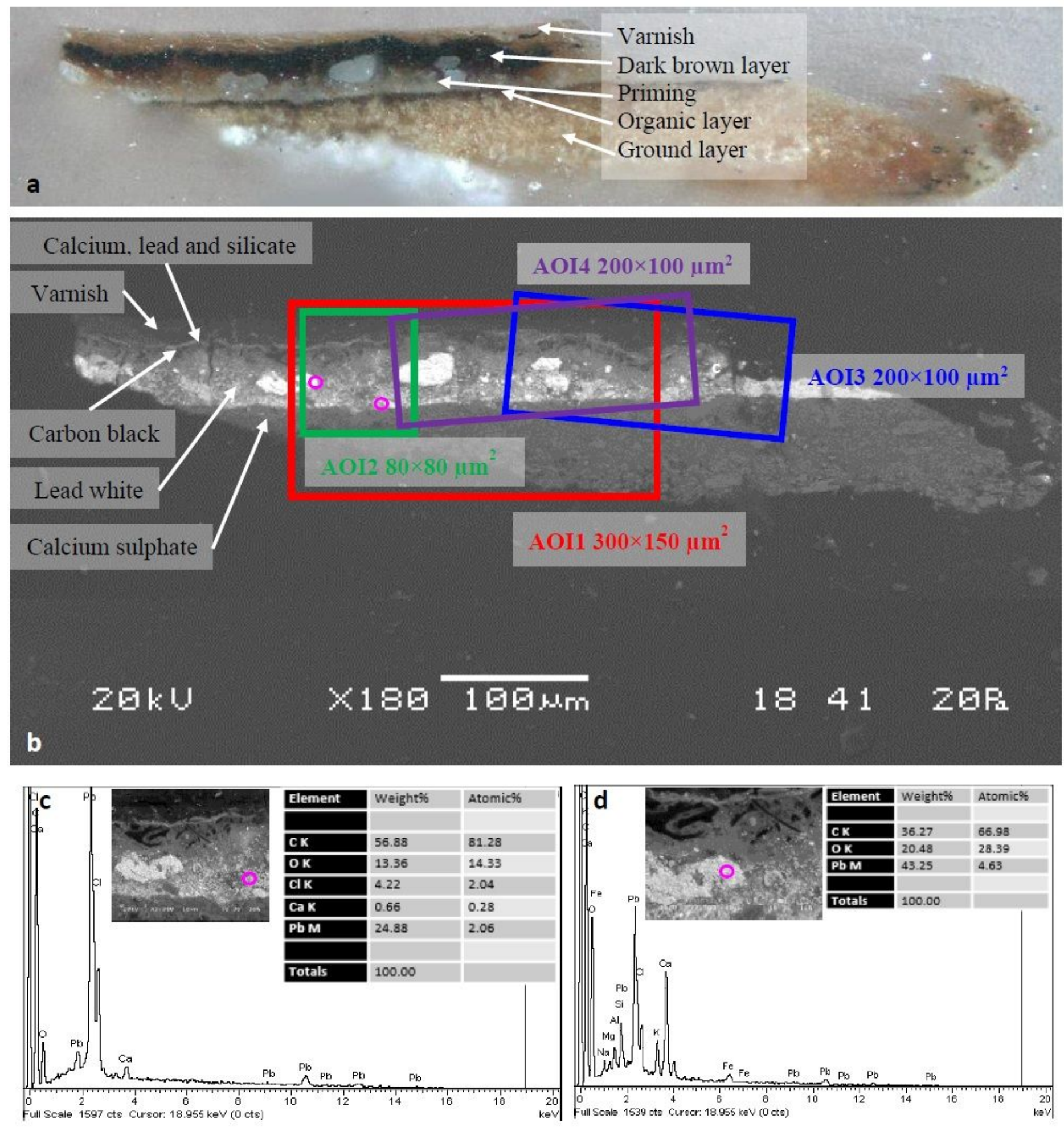

\section{Figure 1}

Optical (a) and SEM (b) images of the paint cross-section from the Adoration of the Magi. The three layers of interest are labeled in (a) and (b). The SIMS images were taken from the 4 areas of interest (AOI) shown in (b). Both negative and positive images were acquired in the areas in AOI 1-2, while only positive 
in the area in $\mathrm{AOI} 3$, negative in the area in $\mathrm{AOI}$. The areas within Magenta circles were subjected to SEMEDS elemental analysis with result shown in (c) and (d).

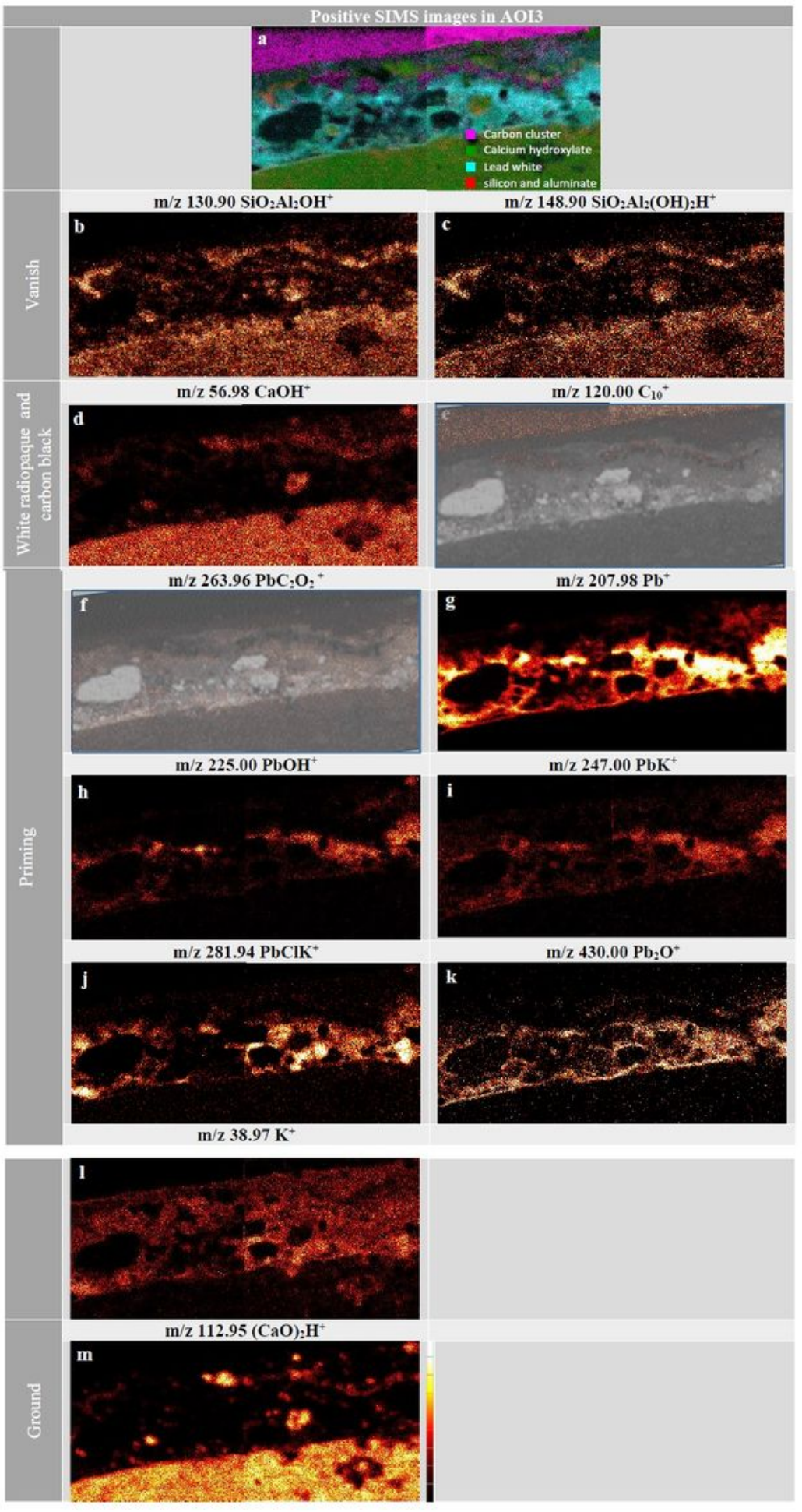

Figure 2

Positive images of paint film in areas of $\mathrm{AOI} 3$ to reveal the chemical composition of each layers identified in SEM image. 


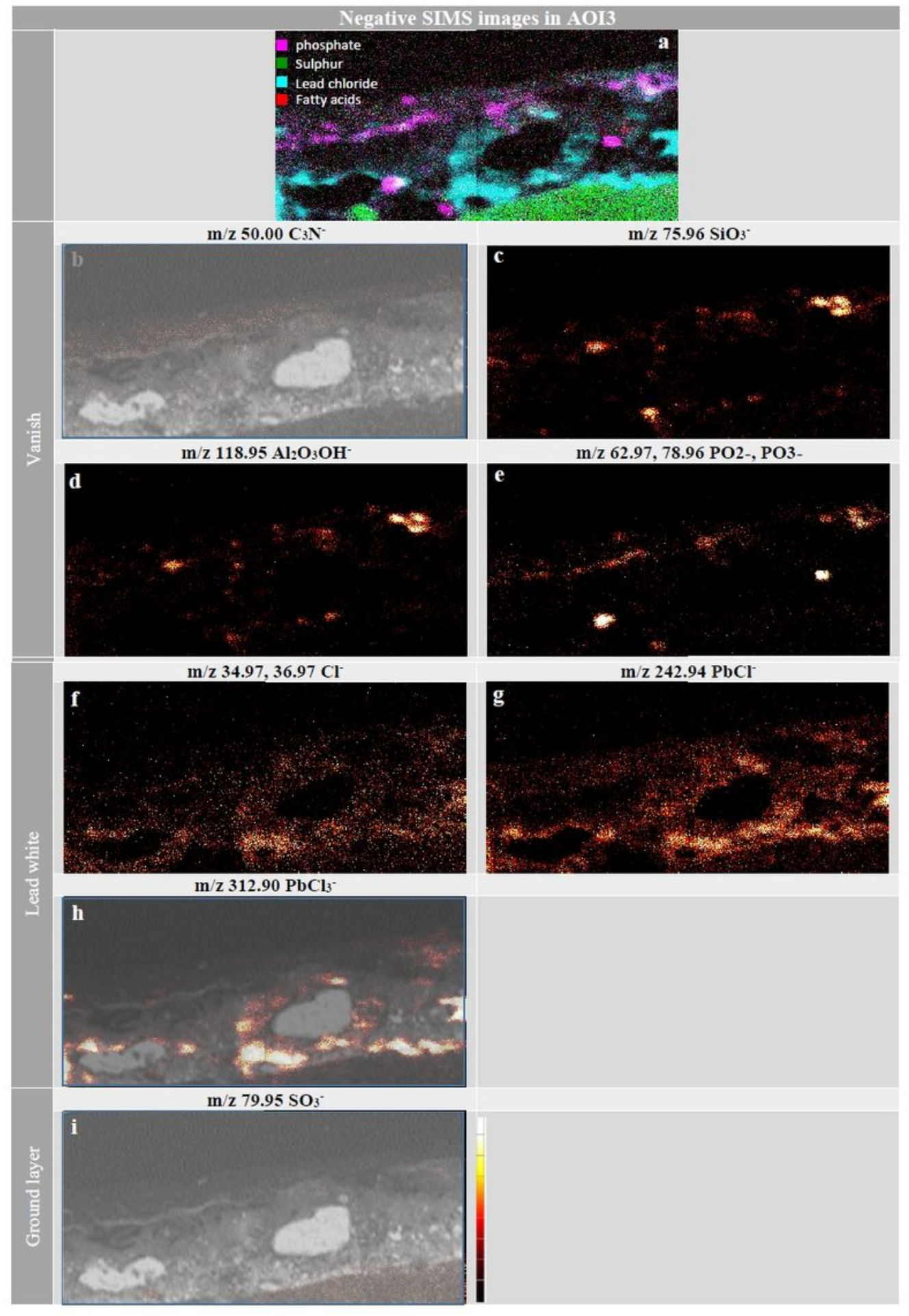

\section{Figure 3}

negative images of paint film in areas of $\mathrm{AOI} 4$ to reveal the chemical composition of each layers identified in SEM image. 

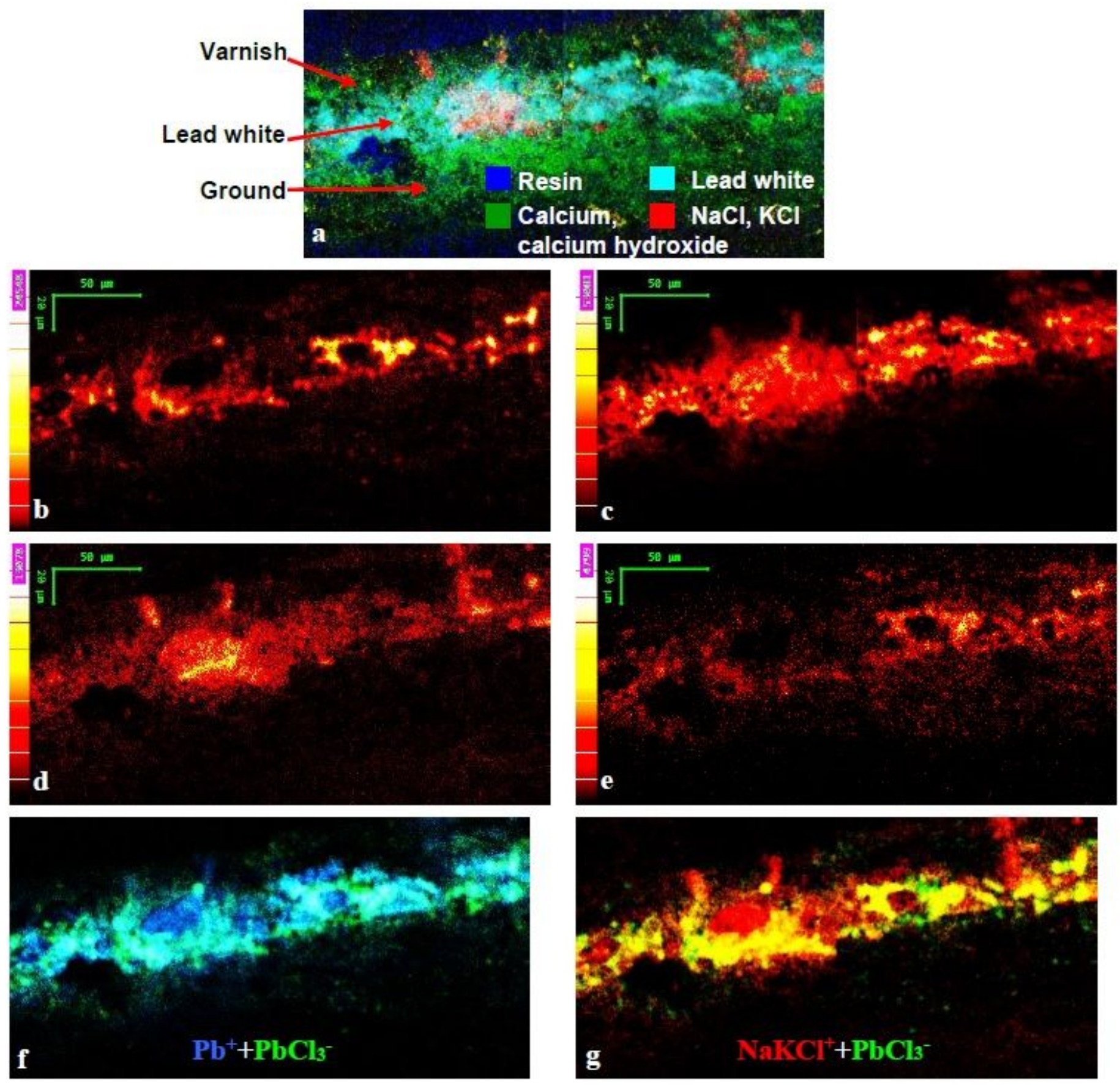

Figure 4

SIMS images from the lead white layer of the paint chip section. The color overlay image shown in (a) reveals the major inorganic components of the different layers, showing the embedding resin $(\mathrm{m} / \mathrm{z} 85.01)$ in blue; calcium (Ca+, $\mathrm{m} / \mathrm{z}$ 39.96) and calcium hydroxide $(\mathrm{CaOH}+, \mathrm{m} / \mathrm{z} 56.97)$ in green; lead ion $(\mathrm{Pb}+$, sum of $\mathrm{m} / \mathrm{z} 207.98,206.98,205.97,203.97)$ in light blue; sodium potassium chloride ( $\mathrm{NaKCl}+$, sum of $\mathrm{m} / \mathrm{z}$ $96.92,98.92)$ in red, which is co-localized with lead ions; copper $(\mathrm{Cu}+, \mathrm{m} / \mathrm{z} 62.93)$ in yellow. Individual components are shown in b-e as follows: (b), $\mathrm{Pb}+$, sum of $\mathrm{m} / \mathrm{z} 207.98,206.98,205.97,203.97$. Other positive ions such as $\mathrm{Pbn}+(\mathrm{n}=1-2), \mathrm{PbnOn}+(\mathrm{n}=1-3), \mathrm{PbnOn}-1 \mathrm{OH}+(\mathrm{n}=1-3)$ have the same distribution. (c), 
$\mathrm{NaKCl}+$, sum of $\mathrm{m} / \mathrm{z}$ 96.92, 98.92. Lead salt adducts $\mathrm{PbNaH} 2+, \mathrm{PbK}+, \mathrm{PbO} 2 \mathrm{Na}+, \mathrm{PbClK}+$ show a similar distribution. (d), $\mathrm{PbCl} 3-$, sum of $\mathrm{m} / \mathrm{z} 310.90,311.90,312.88,313.89,314.87,315.89,316.89$. The $\mathrm{PbCl}$, $\mathrm{PbCl} 2$ - show the same distribution. (e) $\mathrm{HKCl} 3-$, sum of $\mathrm{m} / \mathrm{z} 144.88,146.88$ and 148.87 . The other chloride cluster ions with the same distribution are $\mathrm{NaCl} 2-, \mathrm{KCl} 2-, \mathrm{H} 2 \mathrm{O} \cdot \mathrm{KCl} 2$ - and $\mathrm{K} 3 \mathrm{Cl} 4$ - The relative intensity of these ions can be discerned from the scale bar on the left side of the image. The images in $(f)$ and $(g)$ show color overlays with $\mathrm{Pb}+$ in blue and $\mathrm{PbCl} 3$ - in green. (g) Color overlay image of $\mathrm{NaKCl}+$ in red and $\mathrm{PbCl} 3$ - in green. When the two ions are co-localized the color shows as yellow.
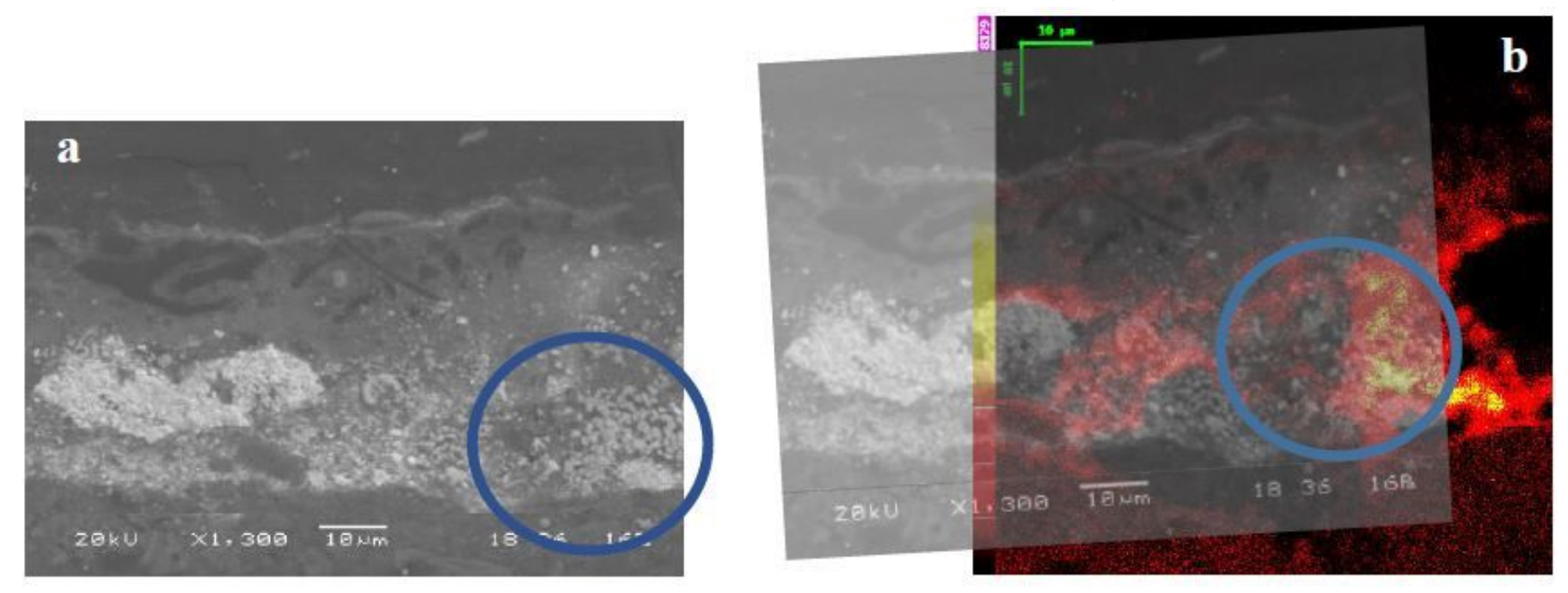

\section{Figure 5}

Small granules of micron dimension are revealed by the SEM image as designated by the blue circle in (a). The SIMS image (b) from this area shows that these granules consist of lead chloride (sum of $\mathrm{m} / \mathrm{z}$ $242.96,240.94,241.97,243.94,244.94)$. A semi-transparent version of the SEM image is superimposed upon the SIMS image to act as a guide to the eye. Related clusters, $\mathrm{PbClK}+, \mathrm{Pb} 2 \mathrm{Cl}+, \mathrm{Pb} 2 \mathrm{Cl} 2+$, exhibit the same distribution.
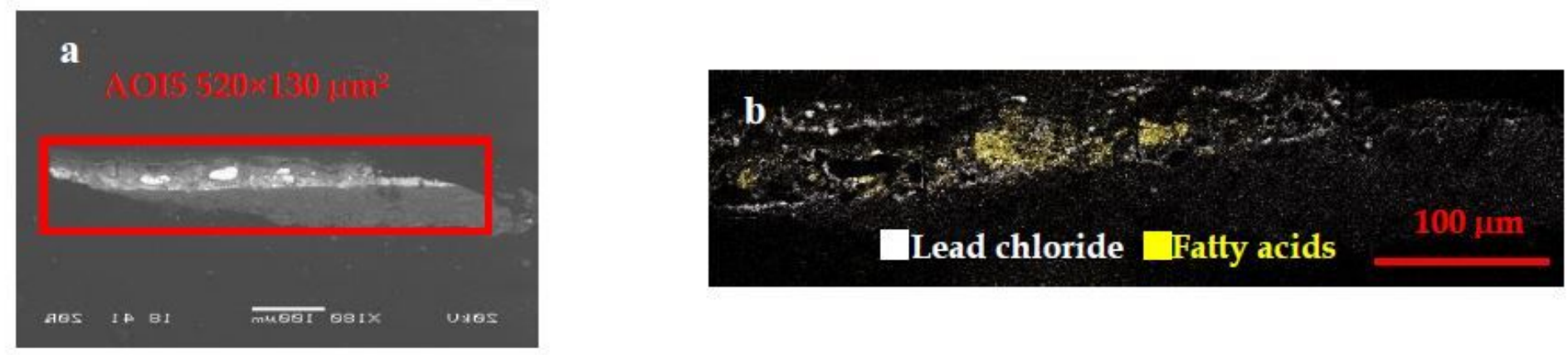

\section{Figure 6}

SIMS imaging of subsurface of paint sample to reveal the oil binding media in the lead white layer. (a) HR SIMS imaging was performance in the area of $520 \times 130 \mu \mathrm{m} 2$ with $2048 \times 512$ pixels as highlighted in SEM image of whole surface area. (b) Color overlay SIMS image of the fatty acids and lead chloride. Fatty 
acids at $\mathrm{m} / \mathrm{z} 255.26$ and 283.25 in yellow are localized within lead white layer characterized by $\mathrm{PbCl}+$ at $\mathrm{m} / \mathrm{z} 242.94$ in white. The composition of fatty acids suggests that the binding media is linseed oil.

\section{Supplementary Files}

This is a list of supplementary files associated with this preprint. Click to download.

- GB.JPG 